\title{
Physician Quality Reporting Initiative (PQRI) - 2009 Update
}

Last year the Center for Medicare and Medicaid Services (CMS) approved the American Board of Family Medicine (ABFM) Performance in Practice Registry as one of 32 qualified registries that may submit Physician Quality Reporting Initiative (PQRI) data to CMS on behalf of its Diplomates. The Medicare, Medicaid, and SCHIP Extension Act of 2007 (MMSEA) authorized CMS to make PQRI incentive payments for satisfactory reporting of quality measures data in 2008. It also established alternative reporting periods and criteria for the reporting of measure groups and for the reporting of PQRI quality measures through an approved clinical data registry.

In 2008, 382 ABFM Diplomates participated in the initiative, which was made available in September. The ABFM has continued as a PQRI registry participant in 2009. In addition to the Diabetes Module, a Preventive Care Module will be added in May 2009.

Table 1. 2009 Diabetes Mellitus Measures Group

\begin{tabular}{clr}
\hline Measure Number & \multicolumn{1}{c}{ Measure Title } & Measure Source \\
\hline 1 & Diabetes Mellitus: Hemoglobin A1c & NCQA \\
& Poor Control in Diabetes Mellitus & NCQA \\
2 & Diabetes Mellitus: Low Density Lipoprotein (LDL-C) & NCQA \\
3 & Control in Diabetes Mellitus & NCQA \\
117 & Diabetes Mellitus: High Blood Pressure Control in Diabetes Mellitus & NCQA \\
119 & Diabetes Mellitus: Dilated Eye Exam in Diabetic Patient & Niabetes Mellitus: Urine Screening for Microalbumin or Medical Attention for \\
$163^{*}$ & Nephropathy in Diabetic Patients & NCQA \\
\hline
\end{tabular}

*New measures added to this measures group for 2009.

NCQA, National Committee for Quality Assurance.

Table 2. 2009 Preventive Care Measures Group

\begin{tabular}{|c|c|c|}
\hline Measure Number & Measure Title & Measure Source \\
\hline 39 & Screening or Therapy for Osteoporosis for Women Aged 65 Years and Older & AMA-PCPI/NCQA \\
\hline 48 & $\begin{array}{l}\text { Urinary Incontinence: Assessment of Presence or Absence of Urinary } \\
\text { Incontinence in Women Aged } 65 \text { Years and Older }\end{array}$ & AMA-PCPI/NCQA \\
\hline 110 & $\begin{array}{l}\text { Preventive Care and Screening: Influenza Immunization for Patients } \geq 50 \\
\text { Years Old }\end{array}$ & AMA-PCPI \\
\hline 111 & $\begin{array}{l}\text { Preventive Care and Screening: Pneumonia Vaccination for patients } 65 \text { Years } \\
\text { and Older }\end{array}$ & NCQA \\
\hline 112 & Preventive Care and Screening: Screening Mammography & NCQA \\
\hline 113 & Preventive Care and Screening: Colorectal Cancer Screening & NCQA \\
\hline 114 & Preventive Care and Screening: Inquiry Regarding Tobacco Use & AMA-PCPI \\
\hline 115 & Preventive Care and Screening: Advising Smokers to Quit & NCQA \\
\hline \multirow[t]{2}{*}{128} & Preventive Care and Screening: Body Mass Index (BMI) & QIP/CMS \\
\hline & Screening and Follow-Up & \\
\hline
\end{tabular}

AMA-PCPI, American Medical Association-sponsored Physician Consortium on Performance Improvement; NCQA, National Committee for Quality Assurance; QIP/CMS, Quality Insights of Pennsylvania/Centers for Medicare \& Medicaid Services. 
This year, physicians who meet the criteria for satisfactory submission of quality measures data for 30 consecutive patients earn an incentive payment of $2.0 \%$ (up from $1.5 \%$ in 2008) of their total allowed charges for Physician Fee Schedule (PFS)covered professional services furnished during the reporting period, January 1, 2009, through December 31, 2009 (the 2009 calendar year). Unlike last year, physicians will not have the option of a 6-month reporting period. For 2009, the only reporting period will be January 1 through December 31, 2009. CMS approved financial incentives earned during 2009 reporting are scheduled to be paid in mid-2010 from the Federal Supplementary Medical Insurance (Part B) Trust Fund.

In addition, a new measure, measure number 163, has been added to the Diabetes Mellitus mea- sures group for 2009. All measures are listed in Tables 1 and 2.

The modules may be accessed without fee for use in participating in PQRI. However, Diplomates who are participating in Maintenance of Certification for Family Physicians (MC-FP) and elect to complete this module to receive Part IV credit are required to submit the appropriate MC-FP processing fee.

For questions regarding PQRI, MC-FP status, or for help with logging in to the Physician Portfolio, call the ABFM Support Center at 877-2237437 or e-mail help@theabfm.org.

Jane Ireland American Board of Family Medicine-Communications 